\title{
A Review of Backup Mechanism for Reducing Delamination when Drilling Composite Laminates
}

\author{
C.C. Tsao ${ }^{\mathrm{a},{ }^{*}}$ and H. Hocheng ${ }^{\mathrm{b}}$ \\ ${ }^{a}$ Department of Mechatronic Engineering, Ta-Hua University of Science and Technology, Hsinchu, 30743 \\ Taiwan, ROC \\ ${ }^{b}$ Department of Power Mechanical Engineering, National Tsing-Hua University, Hsinchu, 30013 Taiwan, ROC
}

\begin{abstract}
Over the past decades, composite materials have been increasingly utilized in various industries because of their superior mechanical properties and resistance to corrosion. Drilling is essential to produce precise holes when loadcarrying structures are produced using composites. Because of the non-homogeneous and anisotropic property of composite laminates, delamination often occurs at the point where the drill exits, which affects reliability and safety. Some studies present a suppressed mechanism to prevent delamination when drilling composite laminates. The experimental results demonstrate delamination is significantly reduced by various suppressed mechanisms and greater feed rates produce the same level of delamination. The use of special drill geometries and backup has been demonstrated to be more advantageous than the use of adapted feed controls. The basis for the future development of a suppression mechanism for drilling composite laminates is determined.
\end{abstract}

Keywords: Composite materials, Drilling, Delamination, Suppressed mechanism, Backup.

\section{INTRODUCTION}

In recent years, composites have become commonly used for the production of structural components for the aerospace, military and transport industries because of their superior mechanical properties. However, the integration of composite structural components still requires assembly processes that require riveting and fastening using drilled holes. For some economic and quality considerations, drilling is the most common method for generating a precise hole. As composites are either non-homogeneous or anisotropic, drilling causes specific damage such as delamination at the exit of the hole and this reduces the bearing and fatigue strength of the composite components [1-3]. Many studies have shown that thrust force is the main cause of delamination [4, 5]. Reducing thrust force at the drill exit can prevent drilling-induced delamination. However, a reduction in the thrust force is not the best solution in terms of the manufacturing process as a whole and the production costs of accommodating a slow drilling process during the manufacture of components that use composite materials are high.

Several studies have reported that a delaminationfree hole is critical in the machining of composite laminates [6-10]. Teti presented an overview of conventional machining of composite materials, such as metal matrix composites and fiber reinforced

*Address correspondence to this author at the Department of Mechatronic Engineering, Ta-Hua University of Science and Technology, Hsinchu, 30743 Taiwan, ROC; E-mail: aetcc@tust.edu.tw composite laminates [6]. Hocheng and Tsao summarized the critical thrust force models for various special drill bits, pilot holes and backup plates and the feasibility of using non-traditional machining to ensure delamination-free drilling of composite laminates [7]. Abrão et al. studied the effects of tool materials and geometry, as well as machining parameters on the thrust force and the drilling quality in drilling composite materials [8]. Liu et al. also summarized progress until 2012 in the mechanical drilling of composite laminates, in terms of drilling operations, drill geometry and materials, drilling-induced delamination and methods for suppressions, thrust force and tool wear [9]. Singh et al. reported an automated drilling operation that produces delamination-free drilling in polymer-matrix composites (PMCs) using a neural network, fuzzy logic, supervisory, proportional-integral (PI), proportionalintegral and derivative (PID), pole placement and adaptive controllers [10]. However, there is no comprehensive study of the mechanical drilling of suppressed mechanisms. This study involves the use of suppression mechanisms that allow delaminationfree drilling of composite laminate.

\section{SUPPRESSION METHODS}

Hocheng and Dharan showed that peel-up at the entry and push-out at the exit are two distinguishable delamination mechanisms that are associated with drilled holes at the periphery of composite laminates [11]. Figure 1 shows the favorable and unfavorable process forces (axial component only) for the drilling of composite laminates. Certain strategies, such as threeaxial milling [12,13] and auxiliary devices [14-17], may 

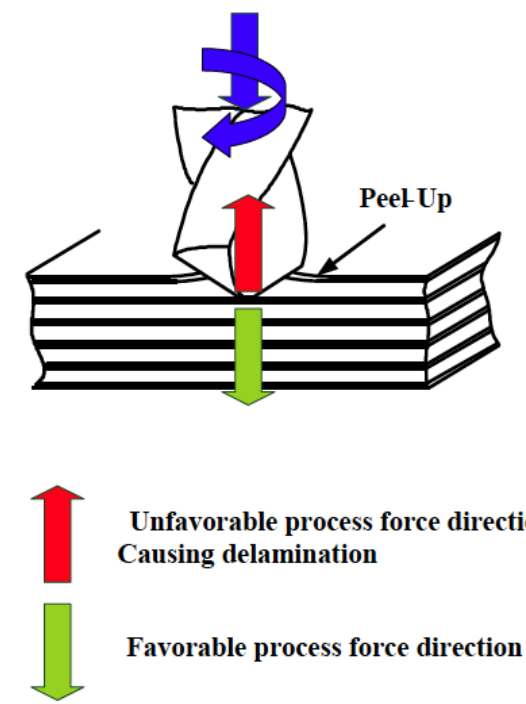
Causing delamination

Favorable process force direction

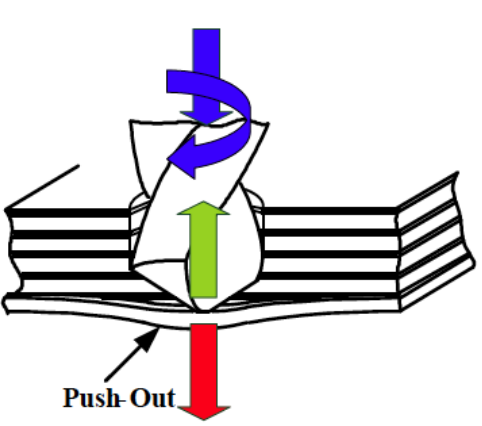

Unfavorable process force direction

Figure 1: Schematic of delamination mechanisms as well as the favorable and unfavorable axial machining force directions.

reduce machining damage and give better drilling quality and longer tool life, as well as greater workpiece strength after machining [18]. Over the past decades, adapted feed controls [19], the use of special drill geometries [5, 20] and backup plates [11, 21-25], which support the outer or remaining layers beneath the workpiece, have been frequently used to reduce pushout delamination for drilled holes. However, peel-up delamination, is not affected by either the presence of a support or the pre-heating. Capello proposed a damping system that reduces delamination by reducing the speed of the drill, relative to the workpiece, during the release stage without the need for backing [26].

\subsection{Passive Backup}

The thrust force during drilling characterizes the machinability of composite laminates and this directly affects the quality of drilled holes. Many studies have reduced the thrust force from tool geometry, machining parameters and the use of passive backup (consumed plate) $[4-10,14]$. Passive backup is a method of supporting the back of a composite laminate to prevent exit delamination and this is commonly used in some manufacturing industries. Hocheng and Dharan first developed a critical thrust force model for twist drills using linear elastic fracture mechanics (LEFM), which is used as a guide to prevent drilling-induced delamination [11]. Hocheng and Tsao developed comprehensive analytical models for critical thrust force for saw drills and core drills with a backup plate and compared these with the model for a conventional twist drill without a backup plate $[27,28]$. The theoretical models were shown to be acceptable and are summarized in Table 1. However, the use of passive backup to support a composite laminate during drilling as a backup is not ideal. This increases the cost of the production, especially for large composite components.

\subsection{Active Backup}

In order to overcome the shortcomings of passive backup, some drilling devices that provide active backup force on the back of a workpiece reduce delamination during drilling, without a reduction in the thrust force or the feed rate for the drill bit and the passive plates need most be scrapped. Figure 2 shows drilling-induced delamination at the exit of a hole without and with the active backup, using a twist drill [27]. Figure $\mathbf{2 b}$ shows significant suppression and a reduction in drilling-induced delamination when there is active backup. The active backup force can be a mechanical force (hydraulic, pneumatic, motor and linkage driven) [26], an electromagnetic force [27, 29] or a thermal/cold force [30].

\subsubsection{Simple Electromagnetic Force}

Tsao et al. developed comprehensive analytical models for the critical thrust force for a twist drill with an actively suppressed mechanism and compared this with the model for a conventional twist drill without a backup plate [27]. This is summarized in Table 2 . Figure 3 shows that the critical thrust force when drilling composite laminate is increased when there is an active backup force to suppress the delamination crack as the drill approaches the last lamina. Where $\gamma$ is the ratio between critical thrust force with suppressed position $\left(F_{B}{ }^{*}\right)$ and critical thrust force without suppressed position $\left(F^{*}\right), \xi$ is the distance betweeen radius of drill (c) and radius of suppressed load $\left(c_{R}\right)$, 


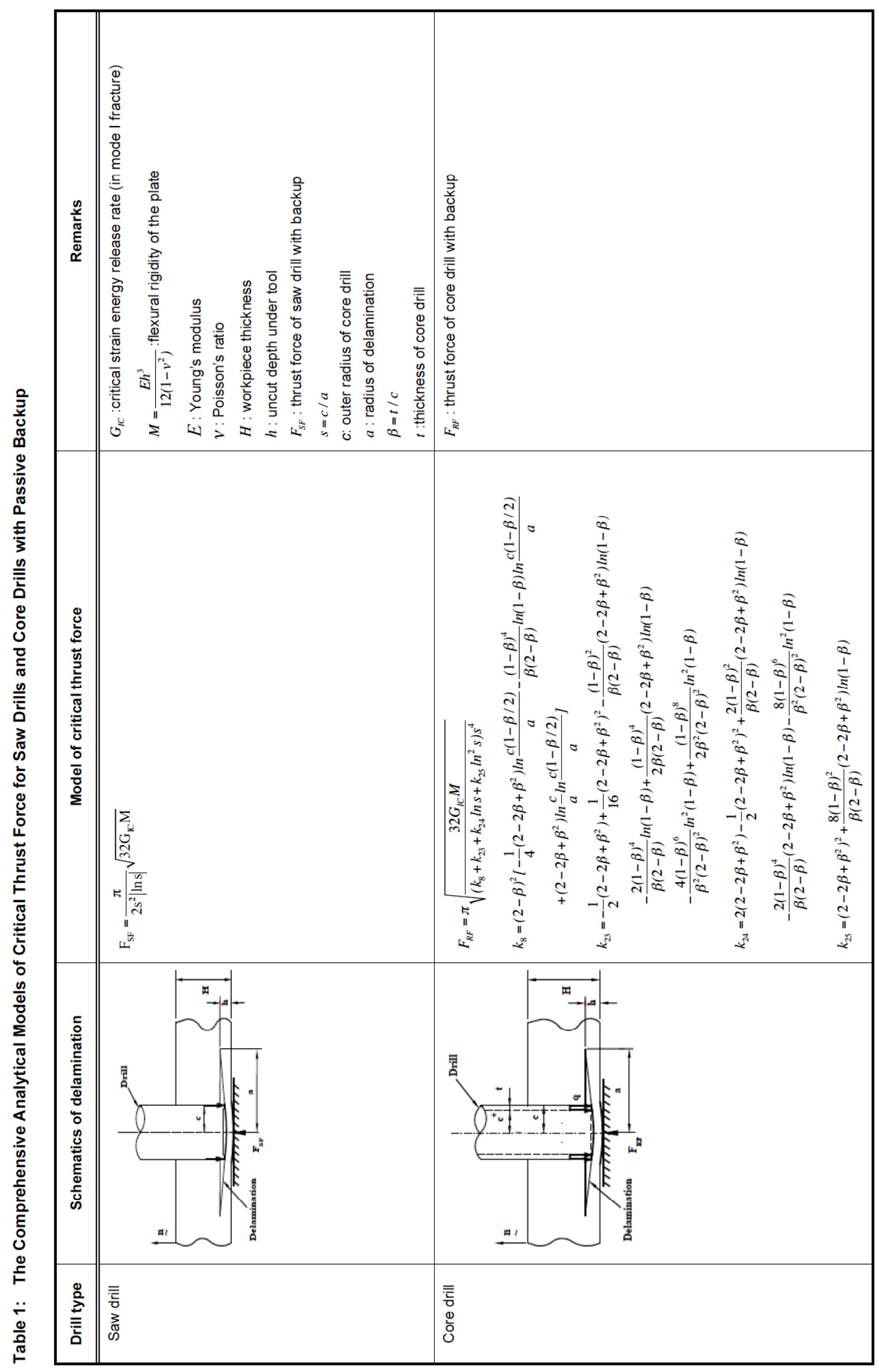




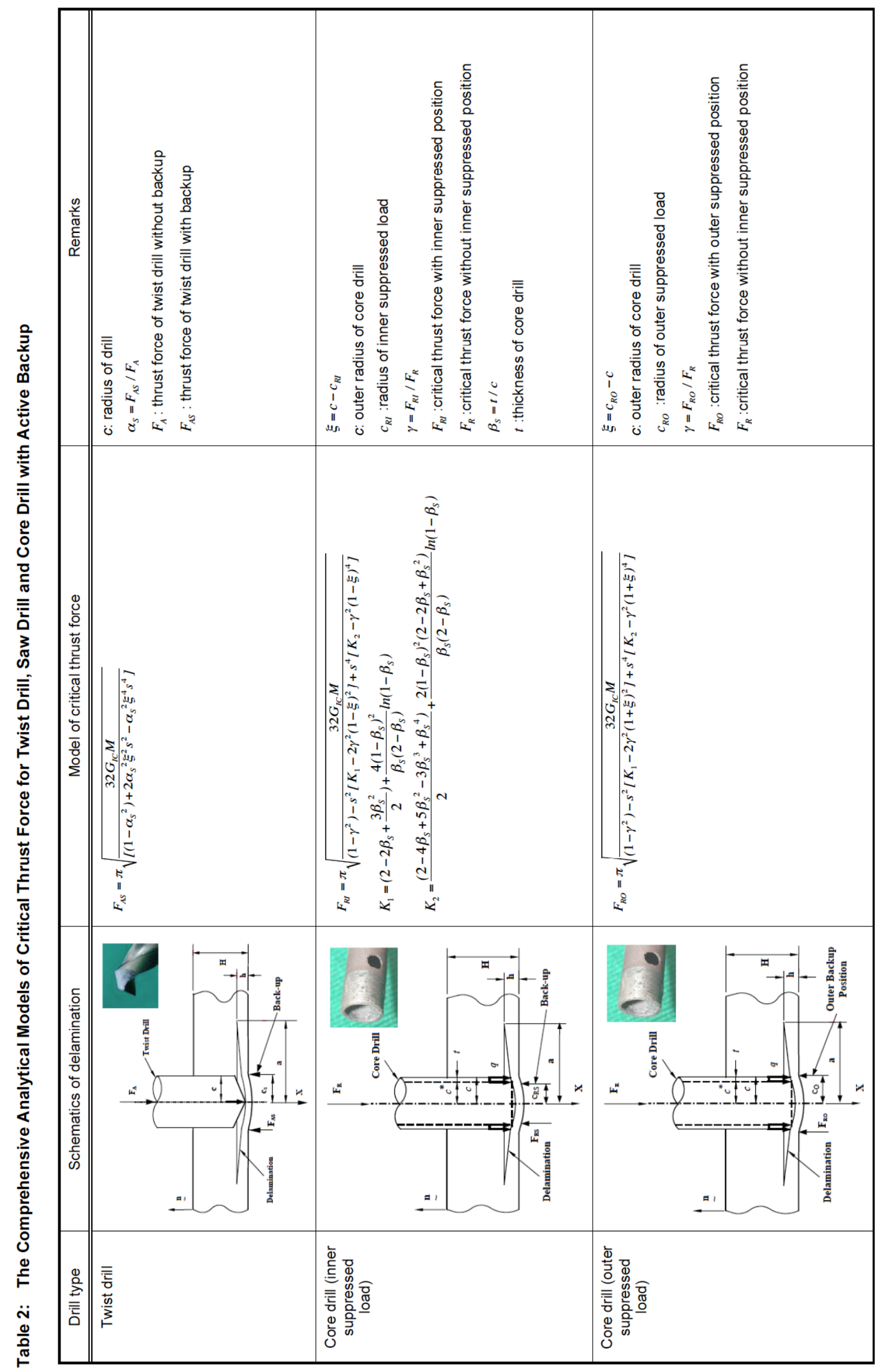




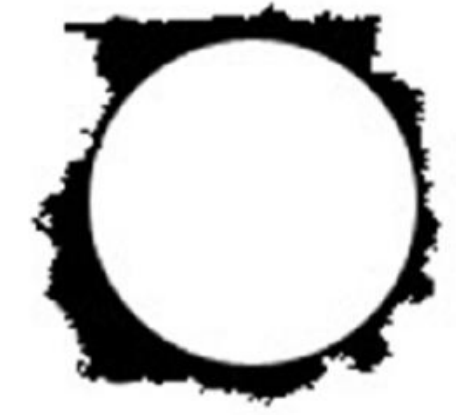

(a) without backup

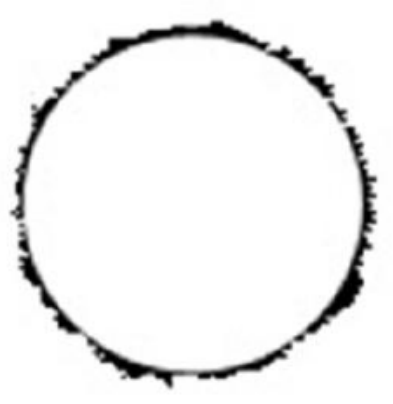

(b) with backup

Figure 2: Extent of drilling-induced delamination (a) without and (b) with active backup [27].

and $s$ is the ratio between radius of drill (c) and radius of delamination (a). Therefore greater drilling thrust is needed to propagate a delamination. Drilling of the composite uses a faster feed rate and there is less risk of delamination. The magnitude of the active backup force is limited to about $\gamma<2$ in practice by the rigidity of the fixture that holds the workpiece during drilling. This effect is very much significant at large value of $s$ when the crack propagates far beyond the drill's diameter. The larger the active backup force, the smaller is the likelihood that the delamination will grow.

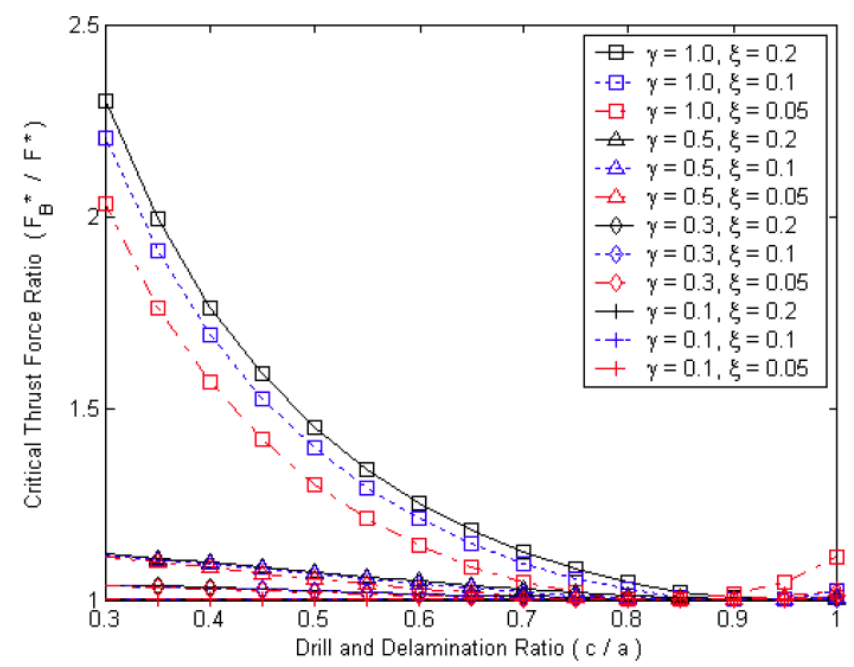

Figure 3: Critical thrust force varying with various levels of $\gamma$ and $\xi$.

Figure 4 shows that the thrust force increases with the feed rate, as commonly seen in practice. The use of backup results in an increase in the drilling force in axial thrust because of the increased rigidity of the structure that is underneath drill bit. The closer distance the suppress load is to the drill bit, namely smaller $\xi$, the more rigid is the structural subject to drilling. This effect is slightly greater at higher feed rates so the thrust force is greater when there is active backup than when there is simple drilling without backup.

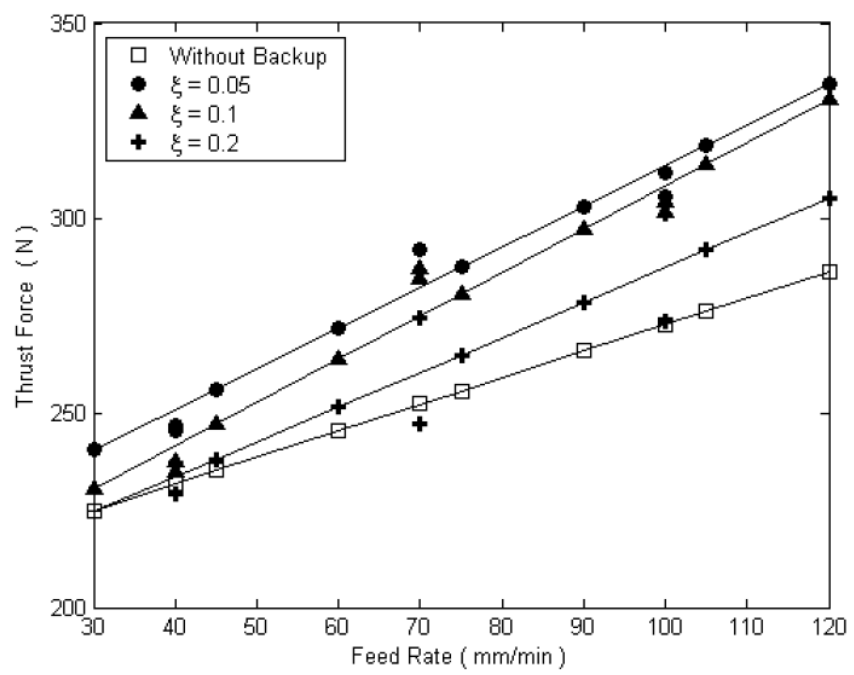

Figure 4: Effects of backup at various location on thrust force.

Figure 5 shows that the extent of any delamination is reduced by $60-80 \%$ at high feed rates when an active backup force is applied. Delamination often

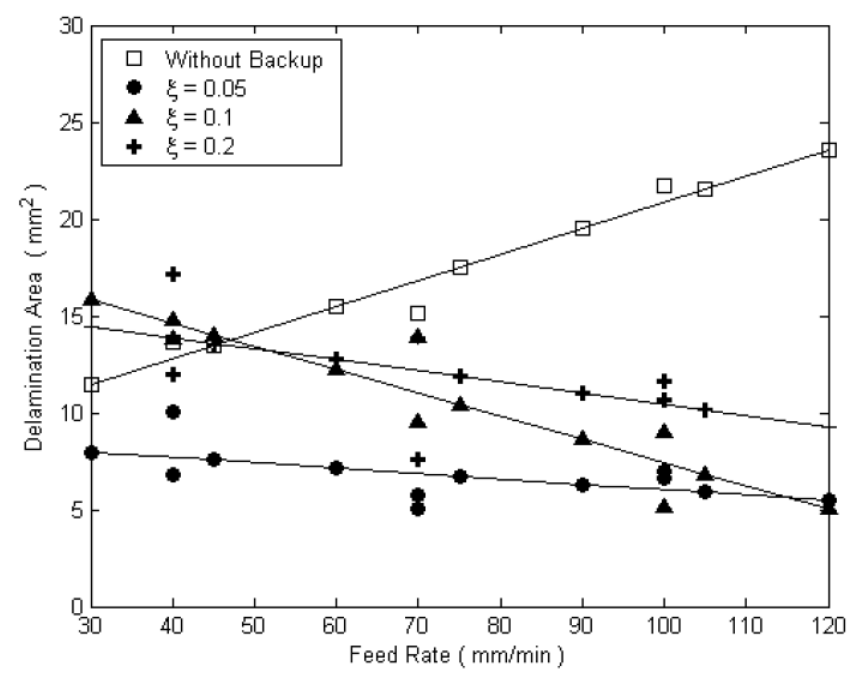

Figure 5: Effects of active backup at various location on delamination reduction. 
increases with feed rates when no backup is provided. When there is active backup, the greater the feed rate, the lesser is the likelihood of delamination. However, when $\xi$ is 0.05 there is less sensitivity on delamination for a given feed rate than when $\xi$ is 0.1 or 0.2 with active backup. Smaller $\xi$ means that there is less bending deformation in the laminate due to pushing by the drill bit.

Figure 6 shows that there is a reduction in delamination when the active backup force is small $(R=13 N)$ and the force is electromagnetic. There is little difference when the backing force is greater, which is advantageous in practice. The effect of a reduction in delamination when the active backup force is small is one of the main causes for the strength of brittle fracture/breakage between CFRP and epoxy resin because of the tool thrust on the last lamina during drilling.

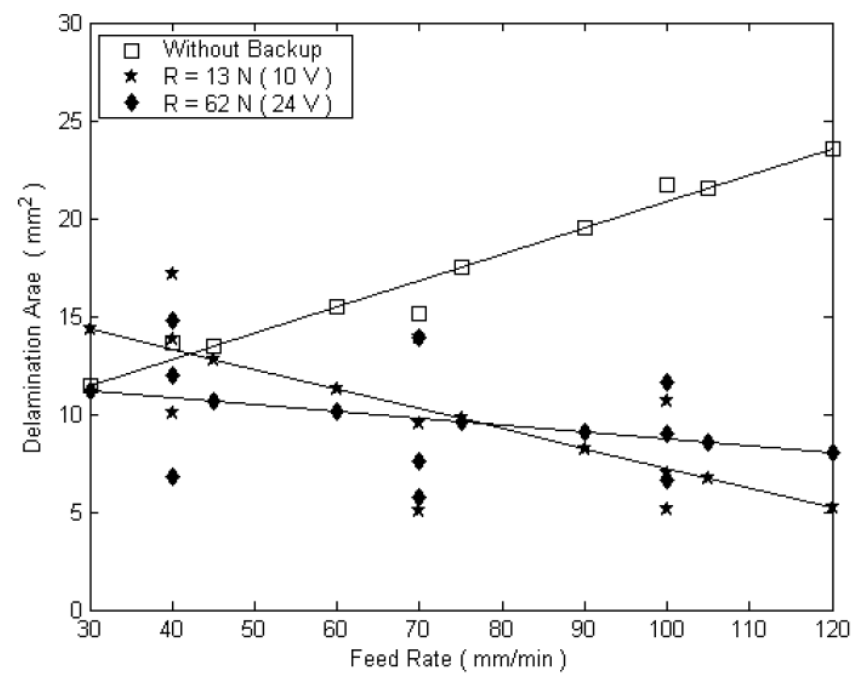

Figure 6: Delamination reduction by active backup.

\subsubsection{Electromagnetic Force and Iron Powder Colloid}

Figure 7 shows schematics for drilling into different surface geometries of composite laminates. Drilling into curved-plate structures produces different degrees of delamination defects on the exit side. Hocheng et al. used an electromagnetic force to suppress the growth of a delamination at the exit side when drilling curvedplate structures using an electromagnet and an inexpensive deformable colloid mixed with iron powder [29]. The area of the delamination is reduced by $60-$ $80 \%$. The optimal volume ratio for powder-to-colloid is $1: 3$.

The feed rate for the drilling of composite laminates determines not only the cutting efficiency, but also the

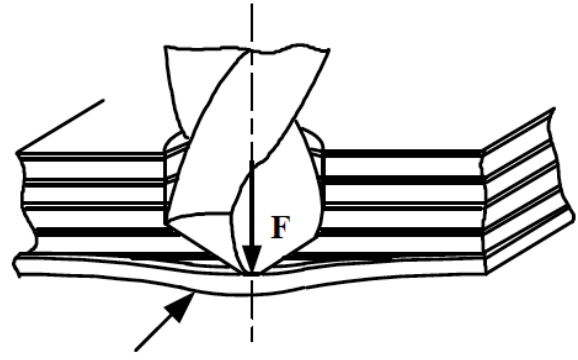

Delamination

(a)

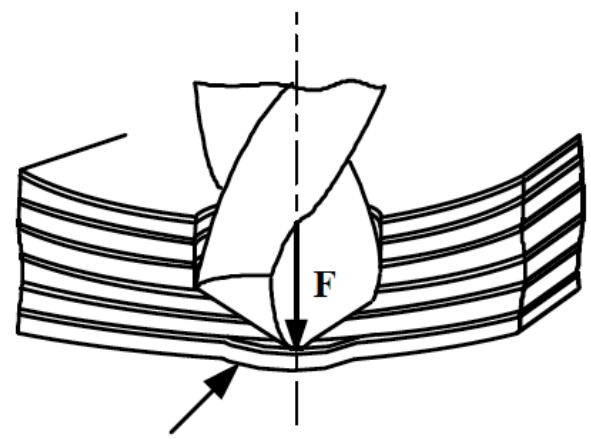

Delamination

(b)

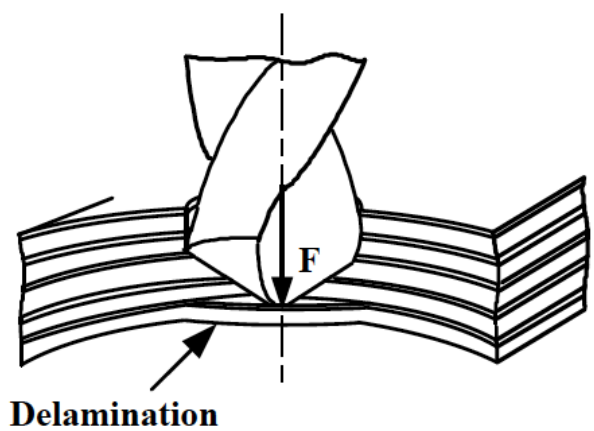

(c)

Figure 7: Drilling composite (a) on a flat plate (b) on a curved plate along curvature and (c) on a curved plate against curvature.

quality of the machined holes. Fast feed rate accompany large thrust, which produces large delamination defects when drilling composite laminates, as shown in Figures 8 and 9. Figure 8 shows that the addition of iron powder generates enough electromagnetic backup to reduce the extent of delamination damage. The initial addition of $12 \mathrm{wt} \%$ results in a reduction of $30-50 \%$, while the addition of $24 \mathrm{wt} \%$ to $36 \mathrm{wt} \%$ does not produce any further effects. Figure 9 shows that a strong electrical current is more effective for electromagnetic backup. A current of $2 \mathrm{~A}$ is required to suppress delamination at fast feed rates.

The area of the delamination when drilling composite laminates becomes smaller as the electrical current increases, as shown in Figures 10 and 11. The 
drilled delamination area at $3 \mathrm{~A}$ is smaller than that at $2 \mathrm{~A}$ and $1 \mathrm{~A}$. Figure 10 shows that the backup effect of $1 \mathrm{~A}$ does not prevent the growth of a delamination when drilling at a high feed rate. However, the reduction of the area of the delamination at $0.1 \mathrm{~mm} / \mathrm{rev}$ is more significant than that at $0.06 \mathrm{~mm} / \mathrm{rev}$ and $0.03 \mathrm{~m} / \mathrm{rev}$, when sufficient electrical current is supplied.

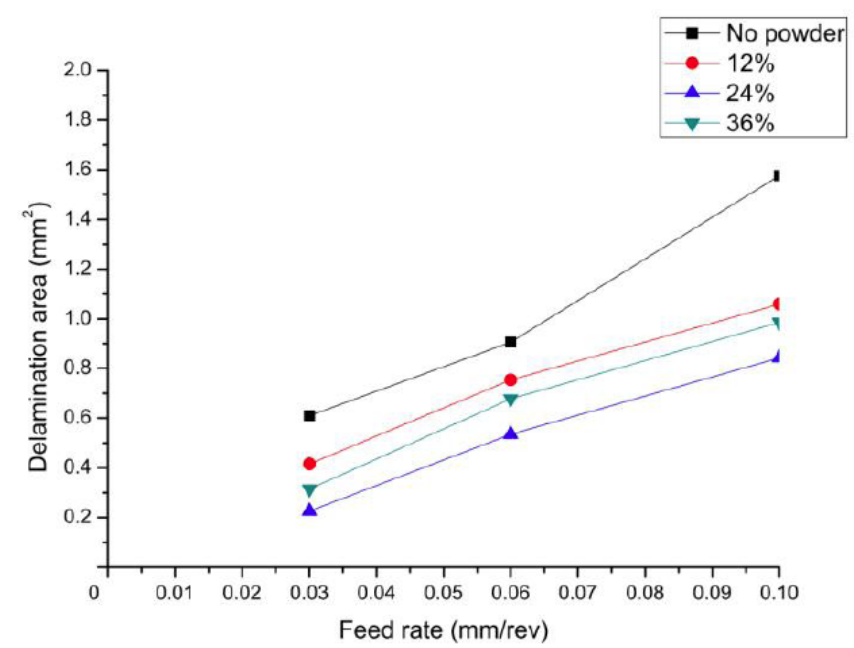

Figure 8: Correlation between delamination area and feed rate at various iron powder volume concentration [29].

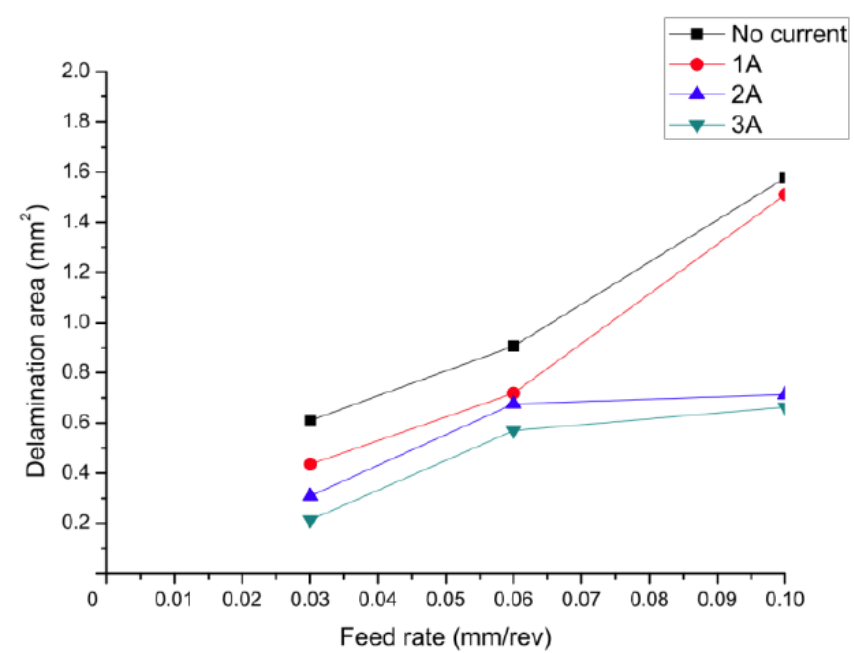

Figure 9: Correlation between delamination area and feed rate at various electrical current [29].

The iron powder provides the desired electromagnetic force for the colloid. More powder produces stronger electromagnetic attraction when drilling. The addition of iron powder into the mixed colloid does not increase the suppression forces proportionally. A greater powder content makes the colloid more viscous so it is less fluid in response to an electromagnetic force. $24 \%$ of iron powder by volume concentration is an optimal value that gives the largest backup force and the associated minimum of delamination when drilling, as shown in Figure 12. This optimal iron powder volume concentration reduces delamination by up to $82 \%$ at low feed rates and by $67 \%$ at fast feed rates.

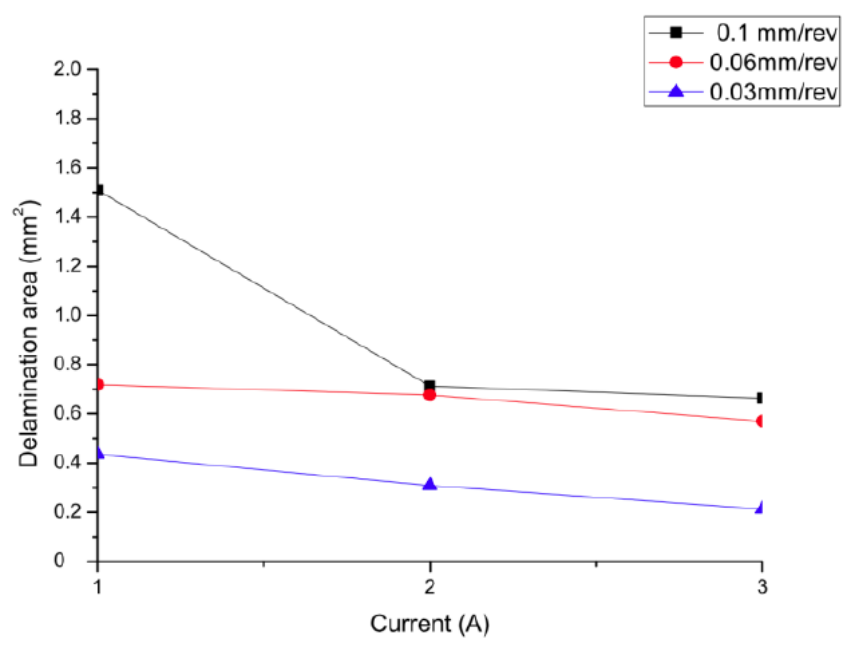

Figure 10: Correlation between delamination area and electrical current at various feed rate [29].

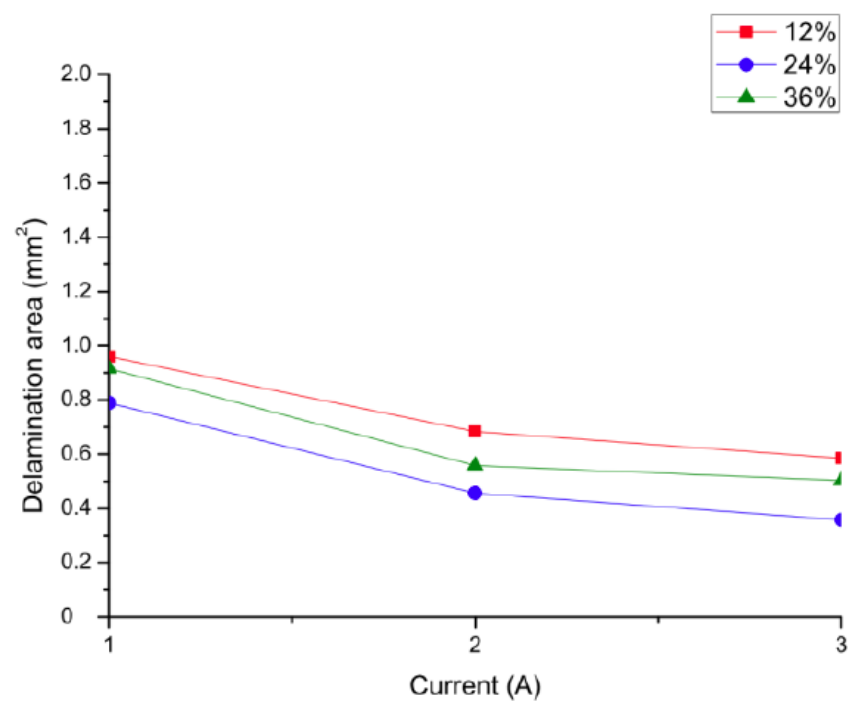

Figure 11: Correlation between delamination area and electrical current at various iron powder volume concentration [29].

\subsubsection{Icing Force}

Figure 13 shows that there is a proportional relationship between the thrust force and the feed rate because of the icing force against delamination when drilling composite tubes. When there is internal icing, the thrust force for drilling increases by $22 \%$ on average. When the spindle speed increases, the thrust force decreases slightly for the same feed rate and drill bit $[9,31-33]$. This is due to the properties of the 


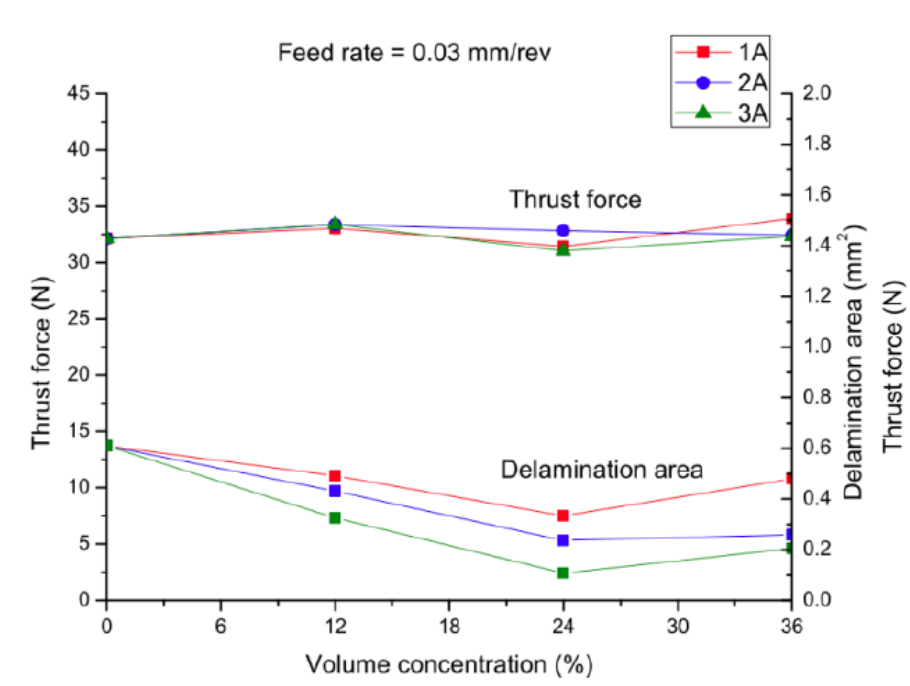

(a) Feed rate $=0.03 \mathrm{~mm} / \mathrm{rev}$

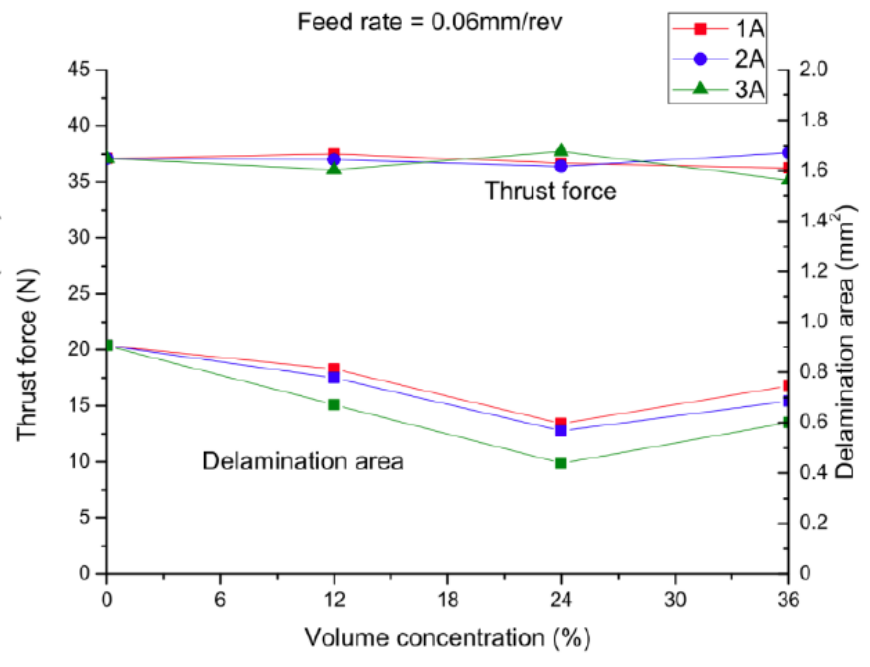

(b) Feed rate $=0.06 \mathrm{~mm} / \mathrm{rev}$

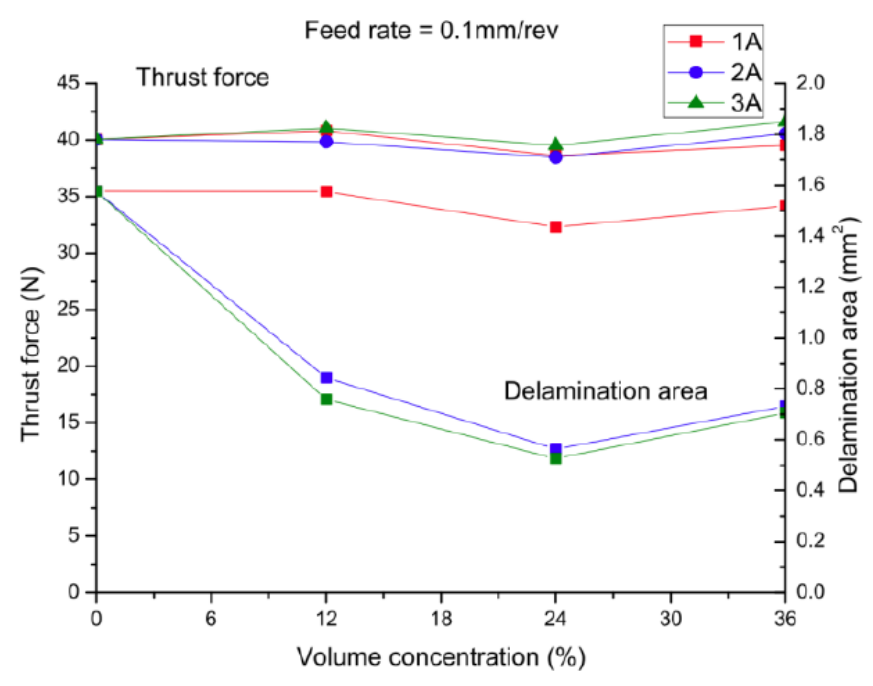

(c) Feed rate $=0.10 \mathrm{~mm} / \mathrm{rev}$

Figure 12: Thrust force and delamination at various powder concentration and electrical current [29].

composite material, in which the matrix is mainly resin polymer. The tensile strength of polymer-matrix composites increases as the ambient temperature decreases so the thrust forces are increased when there is a stronger workpiece. However, the thermal softening effect is slightly greater at higher feed rates. Figure 14 shows the correlation between thrust force and spindle speed without and with backup icing, when drilling composite tubes. The icing-induced lower temperature initially hardens the matrix resin and then the material is softened locally during drilling. The difference in the change in resin strength when there is backup icing is greater than at room temperature. The thrust forces without and with backup icing are respectively reduced by $12.1 \%$ and $12.3 \%$ when the spindle speed is increased from $600 \mathrm{rpm}$ to $1200 \mathrm{rpm}$.
Figure 15 shows the correlation between delamination area and feed rate for various spindle speeds. The drilling-induced energy, which causes delamination, is stored during deformation and becomes surface energy (clustered together crack) when the drill passes through the workpiece. A high feed rate produces a large delamination area. This observation is in agreement with the results for past studies [4, 5, 7-11]. Drilling-induced delamination is reduced for both cases, without and with backup icing operations, as shown in Figure 15. The interlaminate fracture strength is significantly reduced when the temperature is reduced, so the stored bending energy in the laminate during drilling is released to produce a less delamination area. The feed rate can be increased by more than $400 \%$ as the area of the delamination 


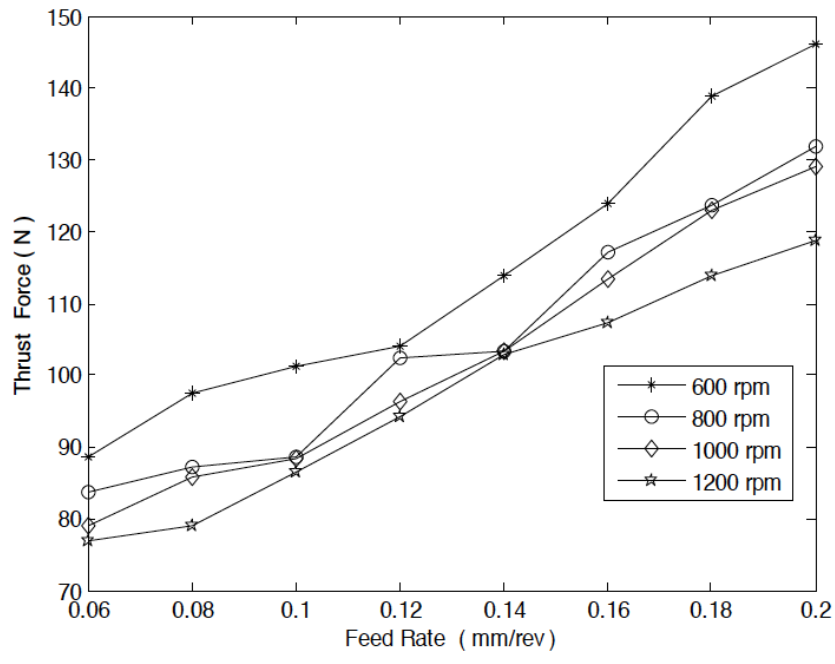

(a) without backup icing

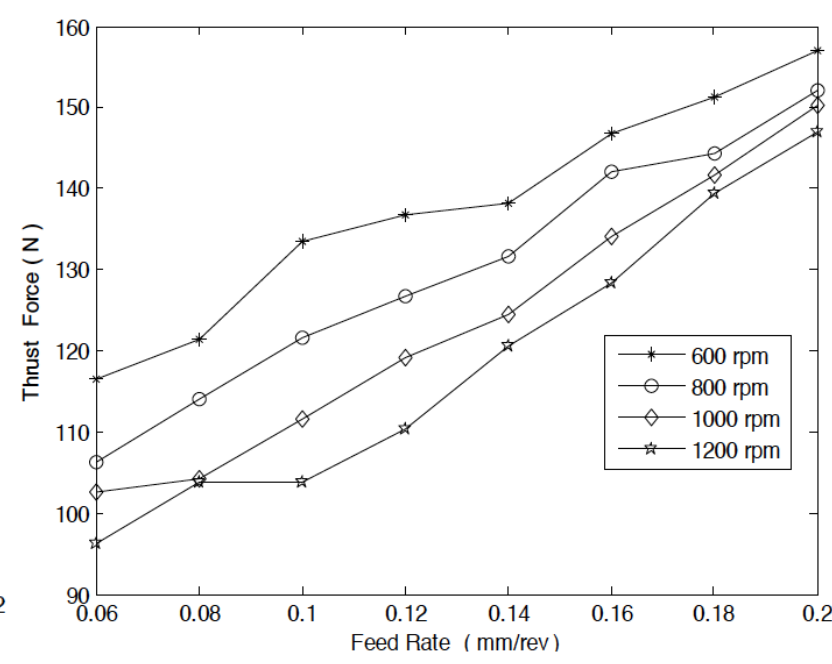

(b) with backup icing

Figure 13: Correlation between thrust force and feed rate (a) without backup icing (b) with backup icing.

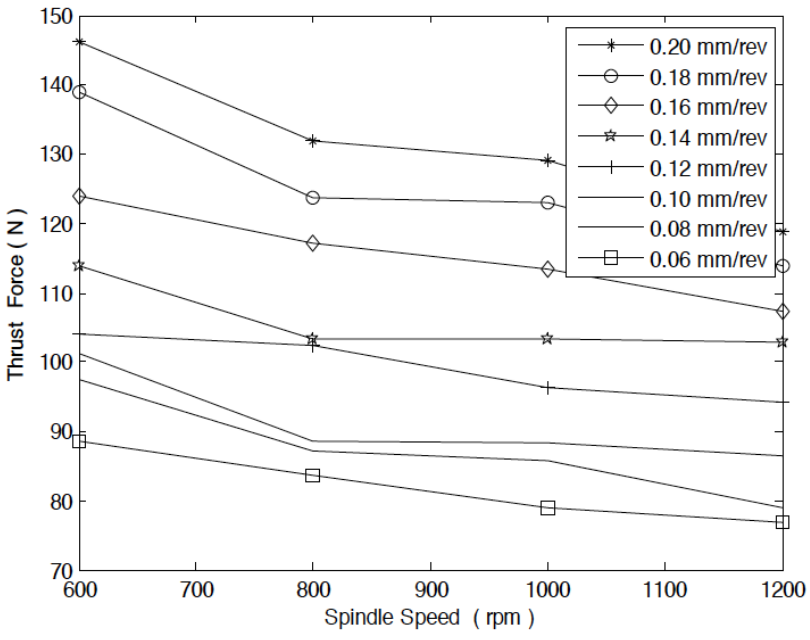

(a) without backup icing

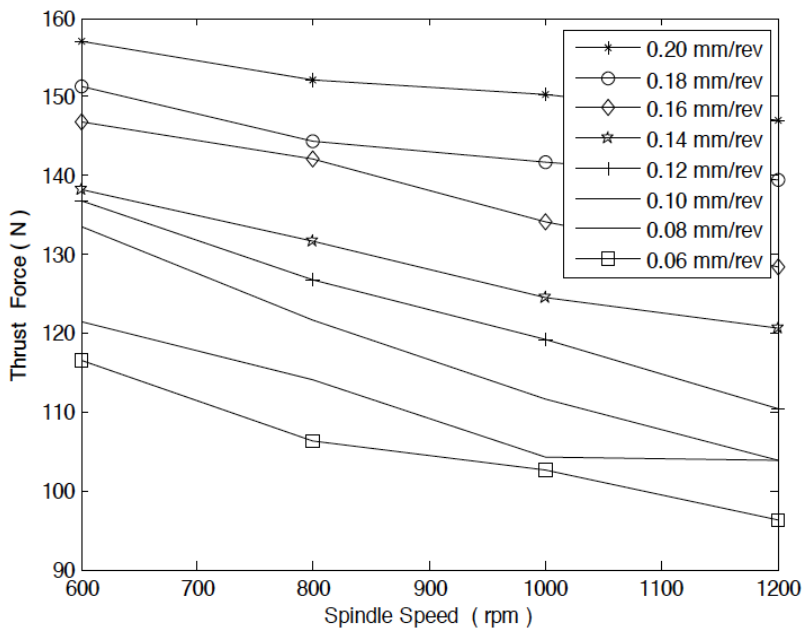

(b) with backup icing

Figure 14: Correlation between thrust force and spindle speed (a) without backup icing (b) with backup icing.

remains the same. When the feed rate is increased from $0.06 \mathrm{~mm} / \mathrm{rev}$ to $0.20 \mathrm{~mm} / \mathrm{rev}$, the delamination remains at $2.5 \mathrm{~mm}^{2}$. The area of the delamination is reduced to more than $40 \%$ when there is internal icing backup, as shown in Figure 16. However, the area of the delamination is less when there is icing than without icing, although the thrust force is greater.

\section{CONCLUSIONS}

Previous studies have rarely focused on the suppression mechanism for the active backup force that reduces delamination when drilling composite laminates. Although using a consumed plate (passive backup force) is a common method of reducing delamination, it is not ideal because it slows production

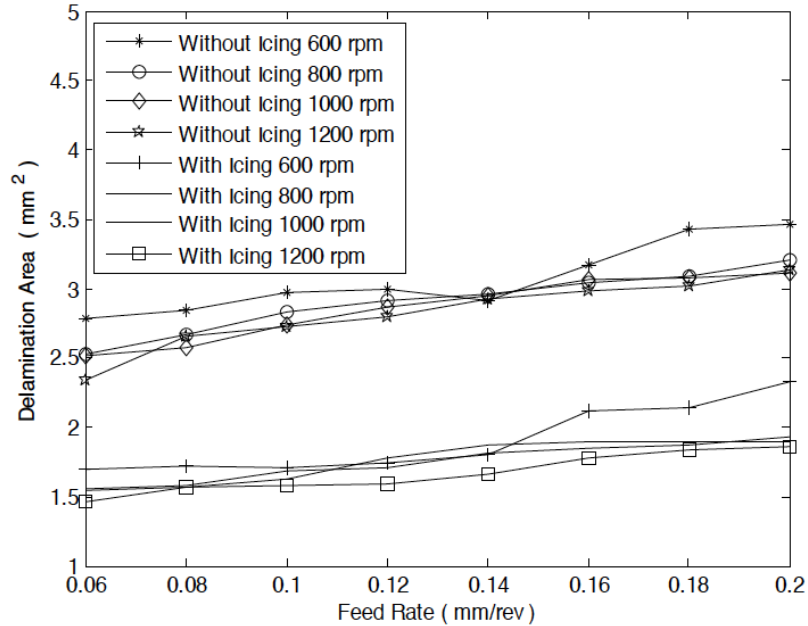

Figure 15: Correlation between delamination area and feed rate. 


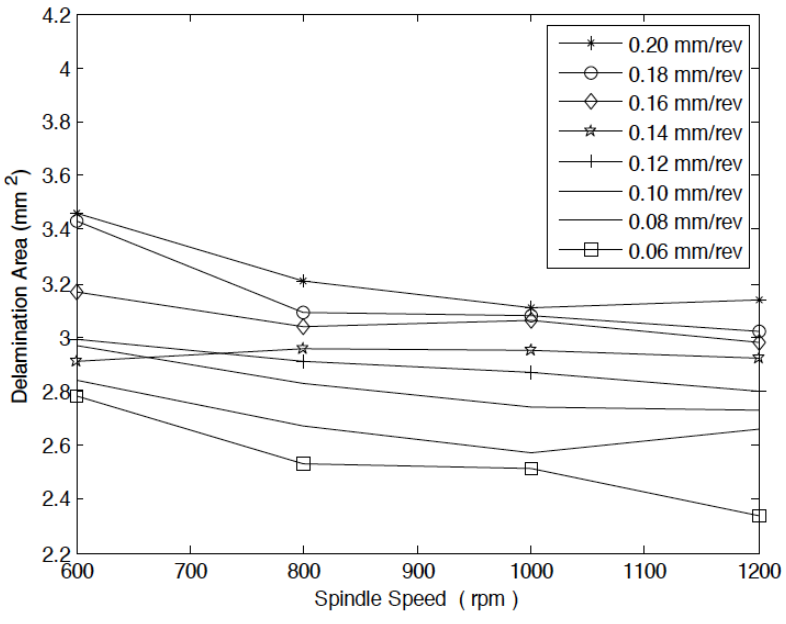

(a) Without backup icing

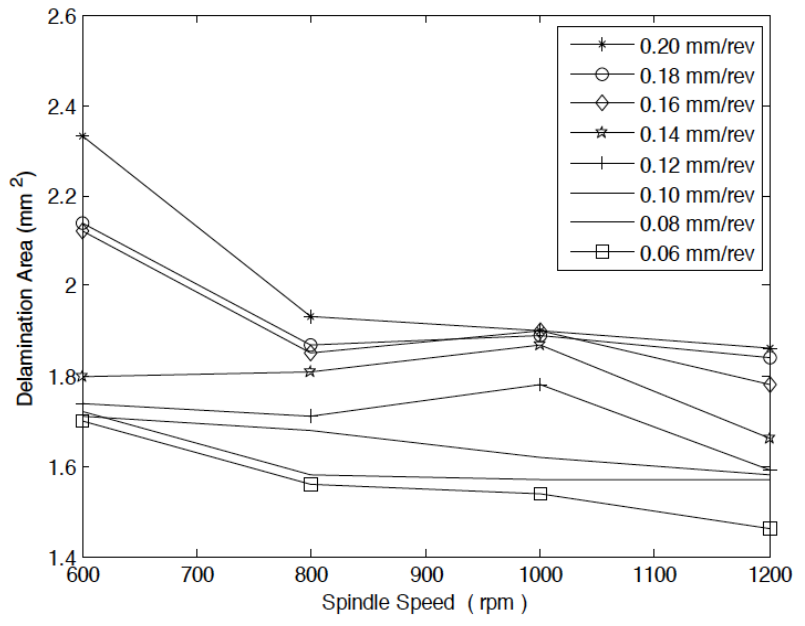

(b) With backup icing

Figure 16: Correlation between delamination area and spindle speed (a) without backup icing (b) with backup icing.

and has economic and quality disadvantage. This study summarizes current methods that use mechanical, electromagnetic and thermal principles when drilling composite laminates. This requires minimal cost and equipment and gives a significant reduction in delamination damage. The method mainly uses a suppression mechanism to provide an active backup force that suppresses drilling-induced delamination during the drilling of composite laminates. The proposed strategies offer an effective and inexpensive method to achieve delamination-free drilling of composite laminates.

\section{ACKNOWLEDGEMENT}

This work is supported by National Science Council, Taiwan, ROC under contracts NSC98-2221-E-007-001MY3, NSC100-2221-E-233-005, NSC100-2221-E-007015-MY3 and NSC103-2221-E-007-136-MY3, respectively.

\section{REFERENCES}

[1] Kim H, Park M, Hsieh K. Fatigue fracture of embedded copper conductors in multifunctional composite structures. Composites Science and Technology 2006; 66(7-8): 10101021.

http://dx.doi.org/10.1016/j.compscitech.2005.08.007

[2] Wei JC, Jiao GI, Jia PR, Huang T. The effect of interference fit size on the fatigue life of bolted joints in composite laminates. Composites Part B: Engineering 2013; 53: 62-68. http://dx.doi.org/10.1016/j.compositesb.2013.04.048

[3] Kapidžić Z, Ansell H, Schön J, Simonsson K. Fatigue bearing failure of CFRP composite in bolted joints exposed to biaxial variable amplitude loading at elevated temperature. Composite Structures 2016; 42: 71-77. http://dx.doi.org/10.1016/j.compstruct.2016.01.064

[4] Koenig W, Wulf C, Grass P, Willerscheid H. Machining of fiber reinforced plastics. Annals of CIRP 1985; 34: 537-548. http://dx.doi.org/10.1016/S0007-8506(07)60186-3
[5] Hocheng H, Tsao CC. Comprehensive analysis of delamination in drilling of composite materials with various drill bits. Journal of Materials Processing Technology 2003; 140: 335-339. http://dx.doi.org/10.1016/S0924-0136(03)00749-0

[6] Teti R. Machining of composite materials. CIRP Annals Manufacturing Technology 2002; 51: 611-634. http://dx.doi.org/10.1016/S0007-8506(07)61703-X

[7] Hocheng $\mathrm{H}$, Tsao $\mathrm{CC}$. The path towards delamination-free drilling of composite materials. Journal of Materials Processing Technology 2005; 167: 251-264. http://dx.doi.org/10.1016/j.jmatprotec.2005.06.039

[8] Abrão AM, Faria PE, Campos Rubio JC, Reis P, Davim JP. Drilling of fiber reinforced plastics: A review. Journal of Materials Processing Technology 2007; 186: 1-7. http://dx.doi.org/10.1016/j.jmatprotec.2006.11.146

[9] Liu DF, Tang YJ, Cong WL. A review of mechanical drilling for composite laminates. Composite Structures 2012; 94: 1265-1279.

http://dx.doi.org/10.1016/j.compstruct.2011.11.024

[10] Singh AP, Sharma M, Singh I. A review of modeling and control during drilling of fiber reinforced plastic composites. Composites: Part B 2013; 47: 118-125.

http://dx.doi.org/10.1016/j.compositesb.2012.10.038

[11] Hocheng $\mathrm{H}$, Dharan $\mathrm{CKH}$. Delamination during drilling in composite laminates. ASME Journal of Engineering for Industry 1990; 112: 236-239. http://dx.doi.org/10.1115/1.2899580

[12] Park KY, Choi JH, Lee DG. Delamination-free and high efficiency drilling of carbon fiber reinforced plastics. Journal of Composite Materials 1995; 29: 1988-2002. http://dx.doi.org/10.1177/002199839502901503

[13] Persson E, Eriksson I, Zackrisson L. Effects of hole machining defects on strength and fatigue life of composite laminates. Composites Part A 1997; 28: 141-151. http://dx.doi.org/10.1016/S1359-835X(96)00106-6

[14] Tsao CC, Hocheng $H$. Effects of exit back-up on delamination in drilling composite materials using a saw drill and a core drill. International Journal of Machine Tools \& Manufacture 2005; 45: 1261-1270.

http://dx.doi.org/10.1016/j.ijmachtools.2005.01.015

[15] Ramkumar J, Malhotra SK, Krishnamurthy R. Effect of workpiece vibration on drilling of GFRP laminates. Journal of Materials Processing Technology 2004; 152: 329-332. http://dx.doi.org/10.1016/S0924-0136(03)00622-8 
[16] Arul S, Vijayaraghavan L, Malhotra SK, Krishnamurthy R. The effect of vibratory drilling on hole quality in polymeric composites. International Journal of Machine Tools \& Manufacture 2006; 46: 252-259. http://dx.doi.org/10.1016/j.ijmachtools.2005.05.023

[17] Babitsky VI, Astashev VK, Meadows A. Vibration excitation and energy transfer during ultrasonically assisted drilling. Journal of Sound and Vibration 2007; 308: 805-814. http://dx.doi.org/10.1016/j.jsv.2007.03.064

[18] Schulze V, Becke C, Weidenmann K, Dietrich S. Machining strategies for hole making in composites with minimal workpiece damage by directing the process forces inwards. Journal of Materials Processing Technology 2011; 211: 329338. http://dx.doi.org/10.1016/j.jmatprotec.2010.10.004

[19] Jain S, Yang DCH. Effects of feed rate and chisel edge on delamination in composite drilling. ASME Journal of Engineering for Industry 1993; 115: 398-405. http://dx.doi.org/10.1115/1.2901782

[20] Hocheng $\mathrm{H}$, Tsao CC. Effects of special drill bits on drillinginduced delamination of composite materials. International Journal of Machine Tools \& Manufacture 2006; 46: 14031416.

http://dx.doi.org/10.1016/j.jjmachtools.2005.10.004

[21] Abrate S, Walton DA. Machining composite materials. Part 1: traditional methods. Composite Manufacturing 1992; 3(2): 75-83. http://dx.doi.org/10.1016/0956-7143(92)90119-F

[22] Konig W, Grass P, Heintze A, Okcu F, Schmitz-Justin C. Developments in drilling, contouring composites containing Kevlar. Production Engineer 1984; 63: 56-61. http://dx.doi.org/10.1049/tpe.1984.0181

[23] Bhattacharyya D, Horrigan DPW. A study of hole drilling in Kevlar composites. Composites Science and Technology 1998; 58(2): 267-283. http://dx.doi.org/10.1016/S0266-3538(97)00127-9

[24] Tsao CC. Effects of passive backup force on delamination in drilling composite materials using twist drill. Advanced Materials Research 2012; 479-481: 213-216. http://dx.doi.org/10.4028/www.scientific.net/AMR.479$\underline{481.213}$
[25] Kundu S, Das S, Saha PP. Optimization of drilling parameters to minimize burr by providing back-up support on aluminium alloy. Procedia Engineering 2014; 97: 230-240. http://dx.doi.org/10.1016/j.proeng.2014.12.246

[26] Capello E. Workpiece damping and its effects on delamination damage in drilling thin composite laminates. Journal of Materials Processing Technology 2004; 148(2): 186-195. http://dx.doi.org/10.1016/S0924-0136(03)00812-4

[27] Tsao CC, Hocheng $\mathrm{H}$, Chen YC. Delamination reduction in drilling composite materials by active backup force. CIRP Annals - Manufacturing Technology 2012; 61(1): 91-94. http://dx.doi.org/10.1016/j.cirp.2012.03.036

[28] Tsao CC. Effect of exit suppressed position on delamination in drilling composite materials using core drill, 17th International Conference on Applied Mechanics and Mechanical Engineering (AMME-17). Cairo Egypt 19th-21st Apr., 2016.

[29] Hocheng H, Tsao CC, Liu CS, Chen HA. Reducing drillinginduced delamination in composite tube by magnetic colloid back-up. CIRP Annals - Manufacturing Technology 2014; 63(1): 85-88. http://dx.doi.org/10.1016/j.cirp.2014.03.070

[30] Hocheng $\mathrm{H}$, Tsao CC, Chen HT. Utilizing internal icing force to reduce delamination in drilling composite tubes. Composite Structures 2016; 139: 36-41. http://dx.doi.org/10.1016/j.compstruct.2015.11.043

[31] Tsao CC, Hocheng $\mathrm{H}$. Analysis of delamination in drilling of composite materials by core-saw drill. International Journal of Materials and Product Technology 2008; 32(2-3): 188-201. http://dx.doi.org/10.1504/IJMPT.2008.018980

[32] Singh I, Bhatnagar N, Viswanath P. Drilling of uni-directional glass fiber reinforced plastics: experimental and finite element study. Material Design 2008; 29: 546-553. http://dx.doi.org/10.1016/j.matdes.2007.01.029

[33] Khashaba UA, El-Sobaty IA, Selmy AI, Megahed AA. Machinability analysis in drilling woven GFR/epoxy composites: part I - effect of machining parameters. Composites: Part A 2010; 41: 391-400. http://dx.doi.org/10.1016/j.compositesa.2009.11.006 